Medhat M. Farghaly

Naser Uama Abdul-Ghaffar

Mohammed Saad Almanee

Adan Hospital, Kuwait

\section{Ruptured Hepatoma: Report of 5 Cases in Arabs}

\section{Key Words}

Liver tumours

Hepatoma

Ruptured hepatoma

Hepatic dearterialization

Hepatic artery ligation

\begin{abstract}
Objective and Importance: Ruptured hepatic tumours are common among South East Asians. They are rare in whites and in Arabs. Arab cirrhotics who develop acute abdominal pain associated with hypovolaemia and evidence of intraabdominal bleeding ought to be suspected of ruptured hepatocellular carcinoma. Clinical Presentation: Five cases of ruptured hepatocellular carcinoma in Arabs are reported. All patients had liver cirrhosis, and radical surgery was not possible due to the advanced stage of the tumour. Two patients who underwent common hepatic artery ligation survived for more than 9 months after the acute episode. The other 3 died in the hospital due to liver failure. Conclusion: Hepatic dearterialization was found effective in controlling bleeding from ruptured hepatoma. Other modalities of management such as hepatic artery embolization or intratumoural alcohol injection have been found effective in controlling bleeding.
\end{abstract}

\section{Introduction}

Ruptured hepatic tumours have been reported among the rare causes of haemoperitoneum [1-4]. Hepatocellular carcinoma is especially prevalent in the regions of Asia and Sub-Sahara Africa, probably due to the high incidence of hepatitis B and hepatitis C infec- tions in these regions [5]. On the other hand the disease is less common in Europe and the US [5]. Male:female ratio is 4:1 [5]. André [3] first reported haemoperitoneum associated with the rupture of primary hepatic tumours in 1851. The reported frequencies of rupture ranged from 10.2 to $14.5 \%$ in areas where hepatoma is common $[1,2,4]$. Reported

\begin{tabular}{ll}
\hline KARGER & (1) 1998 S. Karger AG, Basel \\
Fax +41 61 306 1234 & 1011-7571/98/0074-0292\$15.00/0 \\
$\begin{array}{l}\text { E-Mail karger@karger.ch } \\
\text { www.karger.com }\end{array}$ & $\begin{array}{l}\text { Accessible online at: } \\
\text { http://BioMedNet.com/karger }\end{array}$
\end{tabular}

Dr. Medhat Mohamad Farghaly

PO Box 51601

Riqqa 53457 (Kuwait)

Tel. and Fax +965 3717333 
Table 1. Summary of important findings

\begin{tabular}{|c|c|c|c|c|c|}
\hline No. & Age & Sex & Symptoms & Operative findings & Histopathology \\
\hline Case 1 & 75 & M & $\begin{array}{l}\text { abdominal pain, } \\
\text { distension, irre- } \\
\text { ducible scrotal } \\
\text { hernia }\end{array}$ & $\begin{array}{l}\text { liver showed macronodular } \\
\text { cirrhosis, studded with malignant } \\
\text { deposits; one of them was } \\
\text { ulcerated and bleeding }\end{array}$ & $\begin{array}{l}\text { macronodular cirrhosis, } \\
\text { liver cell carcinoma, } \\
\text { clear cell type }\end{array}$ \\
\hline Case 2 & 50 & M & $\begin{array}{l}\text { upper abdominal } \\
\text { pain and } \\
\text { vomiting }\end{array}$ & $\begin{array}{l}\text { liver cirrhotic with multiple } \\
\text { malignant deposits affecting both } \\
\text { lobes of the liver and greater } \\
\text { omentum; bleeding, ruptured } \\
\text { mass in the right lobe }\end{array}$ & $\begin{array}{l}\text { hepatocellular carcinoma } \\
\text { acinar type, on top of } \\
\text { cirrhotic liver }\end{array}$ \\
\hline Case 3 & 60 & $\mathrm{~F}$ & $\begin{array}{l}\text { abdominal pain } \\
\text { and vomiting }\end{array}$ & $\begin{array}{l}\text { advanced macronodular liver } \\
\text { cirrhosis with actively bleeding } \\
\text { ruptured tumour in the postero- } \\
\text { superior part } 6 \times 8 \mathrm{~cm} \text {; multiple } \\
\text { small multicentric tumours in } \\
\text { both lobes }\end{array}$ & $\begin{array}{l}\text { well-differentiated hepato- } \\
\text { cellular carcinoma on top } \\
\text { of macronodular cirrhosis }\end{array}$ \\
\hline Case 4 & 55 & M & abdominal pain & $\begin{array}{l}\text { liver cirrhotic and shrunken; } \\
\text { ruptured area in the dome of the } \\
\text { liver } 10 \times 10 \mathrm{~cm} \text { in diameter, } \\
\text { blood and liver tissue were expelled }\end{array}$ & $\begin{array}{l}\text { liver cirrhosis with } \\
\text { moderately differentiated } \\
\text { hepatocellular carcinoma } \\
\text { on top }\end{array}$ \\
\hline Case 5 & 28 & M & $\begin{array}{l}\text { abdominal pain } \\
\text { and vomiting }\end{array}$ & $\begin{array}{l}\text { liver cirrhosis, multiple hard } \\
\text { masses involving both lobes } \\
\text { (the biggest, } 7 \times 8 \mathrm{~cm} \text { in diameter, } \\
\text { was actively bleeding); moderately } \\
\text { enlarged spleen }\end{array}$ & $\begin{array}{l}\text { active liver cirrhosis with } \\
\text { moderately differentiated } \\
\text { hepatocellular carcinoma }\end{array}$ \\
\hline
\end{tabular}

$\mathrm{M}=$ Male; $\mathrm{F}=$ female.

causes of rupture include tumour tissue necrosis caused by sudden hypoperfusion [6], minor trauma or changes of intra-abdominal pressure [7], repeated abdominal examination [8], cough and defecation with strain [9] and the sudden changes induced by transcontinental airline flight [10]. Here we report 5 cases of ruptured hepatoma in Arabs (4 males and 1 female). In 2 of the patients repeated vomiting probably precipitated the rupture.

\section{Case Reports}

Case 1

A 75-year-old Kuwaiti male known to have a left scrotal hernia was admitted on November 11, 1981 with colic abdominal pain and distension with a huge, tense, tender irreducible left scrotal hernia (table 1). He was haemodynamically stable. The abdomen was tender all over with muscle guarding. The patient was operated upon through a left inguinal incision. The large hernial sac contained blood coming through the wide internal ring. Laparotomy was performed, and 2 litres of blood were found in the peritoneal cavity. The spleen was moderately enlarged. The liver showed evidence of macronodular cirrhosis and was studded with malignant deposits. Three nodules $5 \times 5 \mathrm{~cm}$ each in diameter, at the lower surface of the liver, were ulcer- 


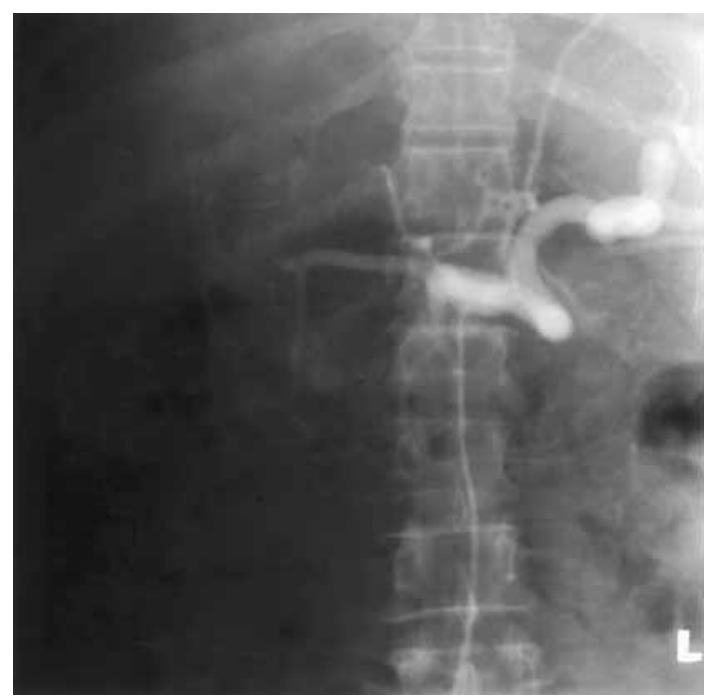

Fig. 1. Coeliac digital subtraction angiography done 2 weeks after surgery showed a ligated hepatic artery. All the vessels seen are abnormal neovessels fed from the gastroduodenal, phrenic and common hepatic (proximal to the ligature) arteries.

ated and bleeding. The bleeding sites were covered with Surgicel (absorbable haemostat made of oxidized regenerated cellulose, manufactured by Johnson \& Johnson) and tampons to arrest the bleeding. Biopsies were taken. Histopathology showed macronodular liver cirrhosis with liver cell carcinoma of the clear cell type. Hepatitis surface antigen (HBsAG) and hepatitis core antibodies (HBcAG) were positive. The patient died due to liver failure 28 days after surgery.

Case 2

A 50-year-old Kuwaiti male was admitted on May 5,1982 . He was a known non-insulin-dependent diabetic and had a 7-year history of duodenal ulcer. He used to drink socially. The patient was admitted to the medical ward with upper abdominal pain of a few hours' duration. A chest X-ray showed healed pulmonary tuberculosis. He deteriorated in a few hours and developed hypovolaemic shock due to massive internal bleeding. The patient was resuscitated with intravenous fluids and blood transfusion. Diagnostic peritoneal tapping revealed blood. An emergency exploratory laparotomy revealed a cirrhotic liver with both lobes studded with degenerated multiple malignant deposits, and that which was situated in the right lobe was actively bleeding. The greater omentum was studded with multiple deposits as well. Bleeding was arrested by multiple sutures, and biopsies taken from the liver and the greater omentum. HBsAG was negative. The patient went into coma due to liver failure and died $48 \mathrm{~h}$ after surgery. Histopathology showed hepatocellular carcinoma of the acinar type on top of a cirrhotic liver.

\section{Case 3}

A 60 -year-old Saudi female presented on July 14, 1988 with a 12 -hour history of persistent vomiting followed by a sudden onset of upper abdominal pain. The patient was in a state of hypovolaemic shock. Her abdomen was distended all over with guarding and absent bowel sounds. Intravenous fluids and blood were administered for resuscitation. Abdominal ultrasonography showed free intraperitoneal fluid, and peritoneal tapping showed blood. An exploratory laparotomy revealed 1.5 litres of intraperitoneal blood. The liver was shrunken due to advanced macronodular cirrhosis. There was an actively bleeding ruptured tumour in the posterosuperior part of the liver $6 \times$ $8 \mathrm{~cm}$ in diameter and with a large blood clot. The tumour was removed and the bleeding at the base was controlled by catgut sutures. There were additional small multicentric tumours in both liver lobes. Histopathology showed well-differentiated hepatocellular carcinoma on top of macronodular cirrhosis. HBsAG was negative. Postoperatively the patient developed disseminated intravascular coagulopathy (DIC) and hepatocellular failure. She died 13 days after surgery due to massive gastro-intestinal bleeding.

Case 4

A 55-year-old Egyptian male presented on November 16, 1989 with severe right hypochondrial pain radiating to the right shoulder. The patient was known to have diabetes, old anteroseptal myocardial infarction and advanced post-hepatitic liver cirrhosis with portal hypertension and oesophageal varices (HBsAG positive). On examination the patient was in a state of hypovolaemic shock. The abdomen was tender and rigid all over. Intravenous fluids and blood were administered. Ultrasonography showed free fluid in the peritoneal and the left pleural cavities. Both peritoneal and left pleural aspirations revealed blood. An exploratory laparotomy through a midline incision was performed. Two litres of blood were found in the peritoneal cavity. The liver was cirrhotic and shrunken. There was a ruptured area in the dome of the liver, $10 \times$ 
Fig. 2. Abdominal $\mathrm{CT}$ with contrast, 9 months after surgery: irregular liver with multiple nonenhancing hypodense lesions involving both hepatic lobes, one of them occupying most of the right lobe. Massive bilateral pleural effusion.

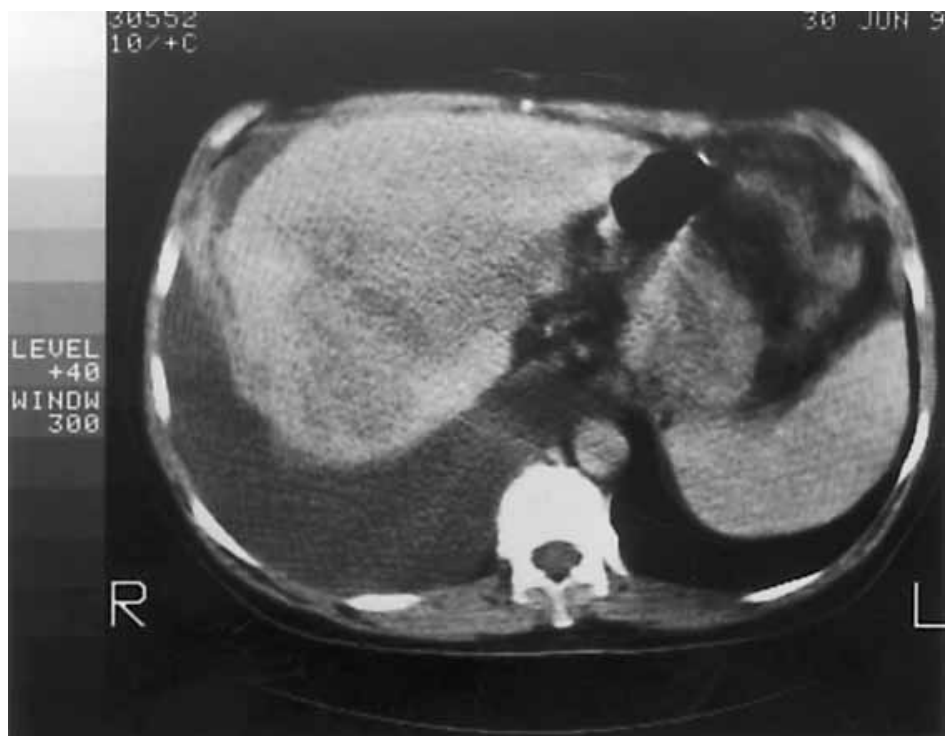

$10 \mathrm{~cm}$ in diameter, from which blood and liver tissues were expelled. Suturing and the application of Surgicel (absorbable haemostat made of oxidized regenerated cellulose manufactured by Johnson \& Johnson) on the bleeding site controlled the bleeding. A liver biopsy was taken. An intercostal tube together with a drain in the right subphrenic space was inserted. Twelve hours after surgery the patient was re-examined due to a recurrent bleeding, and 1.6 litres of blood were found in the peritoneal cavity. The previously sutured area was still actively bleeding. Cholecystectomy and hepatic artery ligation were performed to control the bleeding. Histopathology showed moderately differentiated hepatocellular carcinoma on top of the liver cirrhosis. Coeliac digital subtraction angiography 2 weeks after surgery showed a ligated common hepatic artery with abundant neovascularity (fig. 1). Abdominal computed tomography (CT) with contrast taken in August 1990 showed irregular liver with multiple non-enhancing hypodense lesions involving both hepatic lobes, together with massive bilateral pleural effusion (fig. 2). The patient did well until he travelled back to Egypt in August 1990 and was lost for follow-up.

\section{Case 5}

A 28-year-old Syrian male presented on August 14, 1995 with a 1-day history of epigastric pain and persistent vomiting. An examination revealed generalized abdominal tenderness and rigidity mainly on the right side. Abdominal ultrasonography showed increased liver echogenicity, big mass in the right lobe of the liver with mixed echogenicity and free intraperitoneal fluid. Peritoneal tapping revealed blood-stained fluid. Following resuscitation with intravenous fluids and blood transfusion, an exploratory laparotomy was performed. About 1.5 litres of intraperitoneal blood were found. The liver was cirrhotic with multiple hard masses, involving both lobes, and the spleen was moderately enlarged. The largest mass $(7 \times 8 \mathrm{~cm}$ in diameter) was actively bleeding. The mass involved most of the right lobe, extended into the left lobe, and was related to the gall bladder fundus. The hepatic artery was ligated, a portion of the fungating mass was resected and the gall bladder was removed. Liver and lymph node biopsies were taken. The defect in the liver was closed by an omental patch. Histopathology showed active liver cirrhosis with moderately differentiated hepatocellular carcinoma. The gall bladder and lymph nodes were not infiltrated. HBsAG was negative. An abdominal CT 12 days after surgery showed a large mixed mainly hypodense space-occupying lesion in the anterior segment of the right lobe of the liver, extending to the left lobe. The patient was discharged after 2 weeks, and returned to Syria after 3 months. We failed to receive a feedback information from the relatives about his condition after 5 months of his departure. 


\section{Discussion}

As compared to the Chinese, rupture of hepatocellular carcinoma is rare in whites [11] and very rare in Arabs [6]. To the best of our knowledge only 2 cases of ruptured hepatoma have been reported in Arabs [6]. All our patients were Arabs, and all of them presented with upper abdominal pain, signs of internal bleeding and hypovolaemic shock. Cases 3 and 5 had persistent vomiting for several hours before the onset of internal bleeding. Vomiting is an unusual symptom associated with ruptured liver tumours [2, 12]. It seems likely that vomiting in these patients precipitated rupture. Cases 1, 2, and 5 showed no obvious causes for rupture. All patients had advanced liver cirrhosis and radical surgery was not possible due to the advanced stage of the tumour. Because this condition is so uncommon, the diagnosis is rarely made pre-operatively, especially in a previously healthy patient $[1,2,4$, $6-8,12]$. The diagnosis was made pre-operatively by abdominal ultrasonography only in 1 patient (case 5). One patient was re-explored due to the recurrence of bleeding after local haemostatic measures, and the bleeding was successfully controlled by common hepatic artery ligation. The 2 patients who underwent common hepatic artery ligation survived for a long time (more than 9 months) after the acute episode. The other 3 died in hospital due to liver failure. The prognosis of ruptured hepatoma is extremely bad [1, 2, 4, 6, 7, 12]. Ong and Taw [2] reported 1 case of long-term survival among the 42 patients that were reported. Lai et al. [12] reported a series of 60 patients. Their median survival was 10 days and all of them died within 20 months from the time of diagnosis. Chen and $\mathrm{Au}$ [13] reported a cure after radical surgery in a 10-yearold girl with a ruptured hepatoma in a noncirrhotic liver. In cases 1, 2 and 3 it was possible to arrest bleeding by local measures alone.
In cases 4 and 5 the main hepatic artery had to be ligated to control bleeding. Hepatic dearterialization has been used successfully to control bleeding from ruptured liver tumours in cirrhotic patients [2, 12, 14-17]. Ong and Taw [2] reported 12 cases of ruptured hepatoma that underwent ligation of the hepatic artery. Bleeding was controlled in all of them and their hospital mortality was 50\%. Lai et al. [12] reported 47 patients with hepatic artery ligation. Haemostasis was successful in $68.1 \%$ and hospital mortality was $76.6 \%$. Liver failure was the principal cause of death after surgery $[2,12,15]$. Common hepatic artery ligation has been more frequently used than selective hepatic artery ligation [2, 12, 15]. Both are effective in haemostasis and have similar incidence of liver failure [12]. Arterial embolization has been used to control haemorrhage resulting from spontaneous rupture of hepatocellular carcinoma [16, 17]. Hirai et al. [16] reported 47 cases, 14 of whom underwent emergency transcatheter arterial embolization. The others were treated by supportive measures. The mean survival was significantly higher in the arterial embolization group ( 98.5 days as compared with 13 days). Hsieh et al. [17] reported 17 patients with internal bleeding due to ruptured hepatocellular carcinoma treated with superselective arterial embolization of the artery supplying the tumour. Twelve of them survived the acute episode and their median survival was 5 months. Arterial embolization seems to be a promising line of treatment for ruptured hepatocellular carcinoma. Median survival was significantly longer in patients treated with arterial embolization when compared to those treated with surgery or supportive measures. This line of treatment needs further evaluation and requires wellequipped centres and highly trained personnel. Moreover, follow-up should be maintained as patients who travel back to their home country are lost for follow-up. 


\section{References}

1 Urdaneta LF, Nielsen JV: Massive hemoperitoneum secondary to spontaneous rupture of hepatic metastases: Report of two cases and review of the literature. J Surg Oncol 1986;31:104.

2 Ong GB, Taw JL: Spontaneous rupture of hepatocellular carcinoma. BMJ 1972;4:146-149.

3 André A: Cancer du foie avec hémorrhagie dans la cavité du péritoine: Tubercules dans le poumon. Bull Soc Anat Paris 1851;26:237240.

4 Balasegaram M: Spontaneous intraperitoneal rupture of primary livercell carcinoma. Aust NZ J Surg 1968;37:332-337.

5 Isselbacher KJ, Braunwald E, Wilson J, Martin JB, Fauci AS, Kasper DL: Harrison's Principles of Internal Medicine, ed 13. New York, McGraw-Hill, 1994, pp 1496-1497.

6 Al-Wafai, Shanabo A, Al-Adnani MS, Mahajan K: Intraperitoneal bleeding due to spontaneous rupture of hepatocellular carcinoma in two cirrhotic patients. J Kwt Med Assoc 1985;19:157-162.
7 Bettini V: Unusual cases of spontaneous rupture of the liver causing hemoperitoneum during primary and secondary carcinomas of the liver. Arch Vecchi Anat Pathol 1956; 25:345-375.

8 Van Caneghem A, Gelb AM: Hepatic rupture and hemorrhage from metastatic carcinoma of liver. NY State J Med 1970;70:303-305.

9 Coca A, Munne P, Milla J: Hemoperitoneo espontaneo y abdomen agudo por ruptura de tumores hepaticos. Rev Clin Esp 1979;155:8388.

10 Scorer CG: Spontaneous rupture of a hepatic adenoma: A possible hazard of flying. Br J Surg 1969;56: 633-635.

11 Nagasue N, Inokuchi K: Spontaneous and traumatic rupture of hepatoma. Br J Surg 1979;66:248-250.

12 Lai EC, Wu KM, Choi TK, Fan ST, Wong J: Spontaneous ruptured hepatocellular carcinoma. Ann Surg 1989;210:24-28.

13 Chen CL, Au C: Spontaneous rupture of hepatocellular carcinoma in a child: Report of survival. J Pediatr Surg 1989;24:404-405.
14 May ET, Conti S, Fallahzadeh H, Rosenblatt M: Hepatic artery ligation. Surgery 1979;86:536-543.

15 Chearanai O, Plengvanit U, Asavanich C, Damrongsak D, Sindhvananda K, Boonyapisit S: Spontaneous rupture of primary hepatoma: Report of 63 cases with particular reference to the pathogenesis and rationale treatment by hepatic artery ligation. Cancer 1983;51:15321536.

16 Hirai K, Kawazoe Y, Yamashita K, Kumagai M, Nagata K, Kawaguchi $\mathrm{S}$, Abe M, Tanikawa K: Transcatheter arterial embolization for spontaneous rupture of hepatocellular carcinoma. Am J Gastroenterol 1986;81:275-279.

17 Hsieh JS, Huang CJ, Huang YS, Sheen PC, Huang TJ: Intraperitoneal hemorrhage due to spontaneous rupture of hepatocellular carcinoma: Treatment by hepatic artery embolization. AJR 1987;149:715717. 